\title{
Physical Characterization of Breast Implants Submitted to High Energy X-Rays
}

\author{
Caracterización Física de Implantes Mamarios Sometidos a Rayos X de Alta Energía \\ Sandra Johana Patiño Leiva ${ }^{1 *}$, María Cristina Plazas ${ }^{1,2}$, Lisette Barreto $^{1}$ \\ ${ }^{1}$ Universidad Nacional de Colombia \\ ${ }^{2}$ Hospital Universitario Fundación Santafé de Bogotá (FHUSB), Colombia
}

\begin{abstract}
Based on clinical experience and various studies, it has been found that breast prostheses present failures that are related to a radiotherapy treatment. However, there are currently few studies that analyze the impact of radiotherapy on the material of the prosthesis. Accordingly, the aim of this paper is to characterize the material of silicone breast implants with high cohesiveness. In order to carry out the research a characterization based on mechanical tests, rheology, and spectrophotometry and scanning electron microscopy. This was done with the objective of identifying changes in the prosthesis before and after being irradiated with high energy x-ray photons. To perform the study, 4 breast implants were used. These implants were subjected to the aforementioned tests. The researcher repeated the observation in the second and the third month. Finally, when comparing the results, the mechanical changes are shown in the coating. In the internal material small changes were generated in the elastic and viscous modules. To conclude, effective changes were observed after radiotherapy treatment in the prosthetic material.
\end{abstract}

Keywords: Breast Implants, High Cohesive Silicone, Breast Capsular Contracture, Radiotherapy, CA Breast.

\section{Resumen}

En el presente trabajo se caracterizó el material de implantes mamarios de silicona de alta cohesividad, mediante ensayos mecánicos, de reología e imagenológicos: microscopía electrónica de barrido, espectrofotometría y tomografía computarizada como método para posicionar los implantes al ser irradiados con el fin observar si se alteran las propiedades físico-mecánicas de éstas al someterlas a tratamiento con Radioterapia y bajo diferentes dosis y energías de irradiación. La presente investigación estudia las propiedades del material de 4 implantes mamarios y compara los resultados obtenidos para tres meses de observación. Se observan cambios a nivel mecánico. Por un lado, el recubrimiento del cada implante presentó cambios debidos a la dosis de radiación. Por otro lado, el material interno de la prótesis presentó pequeños cambios en sus módulos elástico y viscoso cuando la dosis, no se presentaron cambios apreciables al revisar la energía utilizada y el tiempo de lectura (primer, segundo y tercer mes de observación). En general se observan cambios a nivel mecánico debidos a la dosis de radiación, respecto a la energía utilizada y el tiempo de lectura no hay evidencia de un cambio.

Palabras clave: Implantes Mamarios, Silicona de Alta Cohesividad, Contractura Capsular Mamaria, Radioterapia, CA Mama.

*Corresponding Author.

E-mail: sipatinol@unal.edu.co
How to cite: Patiño, S., Plazas, M., Barreto, L., Physical Characterization of Breast Implants Submitted to High Energy XRays, TECCIENCIA, Vol. 14 No. 26, 65-71, 2019

DOI: $\underline{\text { http://dx.doi.org/10.18180/tecciencia.2019.26.8 }}$ 


\section{Introduction}

When a woman undergoes a mastectomy, because of different reasons is possible to conduct a breast reconstruction using their own tissue (flaps) or through breast implants placed after a period estimated by the specialist. Radiotherapy is a complement that allows to use high energy photons $(\mathrm{MeV})$ in fractioned doses that vary according to clinical criteria (2Gy or 2.66 Gy until completion of a $50 \mathrm{~Gy}$ or $42.56 \mathrm{~Gy}$ total doses p.e.) in order to prevent relapses in the disease. Obtained results are convenient and present safety. However clinical experience along with several conducted studies show that some alterations in prosthetics start to appear within 3 months of treatment completion [1], and even rupture in some occasions [2], [3]. While one of the causes that triggers implant damage is due to breast capsular contracture (by biological causes), few studies are centered in changes that the material could present exclusively due to radiation. In this study physical and mechanical properties of breast implants are evaluated in order to observe if changes are produced due to radiation.

\section{Materials and Methods}

\subsection{Sample collection}

Four breast implants are used for this study, coming from different labs and lots, which is why they cannot be compared amongst each other. Therefore, a workplan is defined that enables to make individual comparisons. For this, each implant is subdivided in 3 parts, cut by a blade:

1. The first part is Control or reference sample, which is not submitted to any kind of treatment.

2. Second and third samples are submitted to a specific energy treatment $(6 \mathrm{MeV}$ or $15 \mathrm{MeV})$ and dosage (40 Gy, 50 Gy or $100 \mathrm{~Gy}$ ) with the purpose of evaluating possible changes in a single fraction, given that we are only determining the implant response as an inert material to typical energies and in comparable doses (40 Gy or $50 \mathrm{~Gy}$ ) to those used in conventional treatments. The following table resumes the objective and the radiation treatment in each implant.

In order to guarantee a homogenous dose in each sample, they are waterproofed and submerged in a container with water. Under these conditions the sample is placed in the computerized tomograph to take reference images used later in the Eclipse treatment planification system and radiated under the same conditions in the electron linear accelerator as shown on the following image (Figure 1).
Table 1 Characteristics of the non-treated sample

\begin{tabular}{|l|l|l|l|}
\hline Implant ID & Subdivision & Dose Gy & Energy MeV \\
\hline \multirow{3}{*}{$380 \mathrm{CC}$} & Control & 0 & 0 \\
\cline { 2 - 4 } & 3801 & 50 & 6 \\
\cline { 2 - 4 } & 3802 & 50 & 15 \\
\hline \multirow{3}{*}{$305 \mathrm{CC}$} & Control & 0 & 0 \\
\cline { 2 - 4 } & 3051 & 50 & 6 \\
\cline { 2 - 4 } & 3052 & 50 & 6 \\
\hline \multirow{3}{*}{$325 \mathrm{CC}$} & Control & 0 & 0 \\
\cline { 2 - 4 } & 3251 & 40 & 6 \\
\cline { 2 - 4 } & 3252 & 100 & 6 \\
\hline \multirow{3}{*}{$235 \mathrm{CC}$} & Control & 0 & 0 \\
\cline { 2 - 4 } & 2351 & 40 & 6 \\
\cline { 2 - 4 } & 2352 & 100 & 6 \\
\hline
\end{tabular}

The implant's covering passes though the following tests: Infrared Spectrophotometry (IR, UV, VIS), mechanical tests and Scanning Electron Microscopy (SEM), and the prosthetic inner material is only submitted to rheometric tests.

\subsection{Mechanical Tests}

The universal machine for physical tests was used to produce the data of the tractive properties. Such tests were submitted to the breast implants covering, cutting samples with a die cutter with the geometry recommended by the ASTM D638 norm (Figure 2). Elongation percentage, stress, deformation and elastic modulus were evaluated. The following definitions are extracted from the D638 norm [4].

Tractive Force: Calculates the resistance to traction, by dividing the maximum charge supported by the sample, in Newton, by the calibrated cross-section, in $\mathrm{m} 2$. The resulting units are Pascals.

Elongation Percentage: Is the change in reference length in comparison with the original length of the sample, expressed in $\%$. These values are valid provided that they are within the calibrated length.

Elastic Modulus: Though the linear extension of the stress or applied force curve in function of the elongation distance, the result is obtained in Pascals. The modulus indicates the rigidity of a material: The more rigid it is, higher their elastic modulus.

\subsection{Experimental procedure}

For the optical test a scanning is performed on the prosthetic covering using a VARIAN Cary5000 spectrophotometer (Figure 3). 


\section{TECCIENCLA}

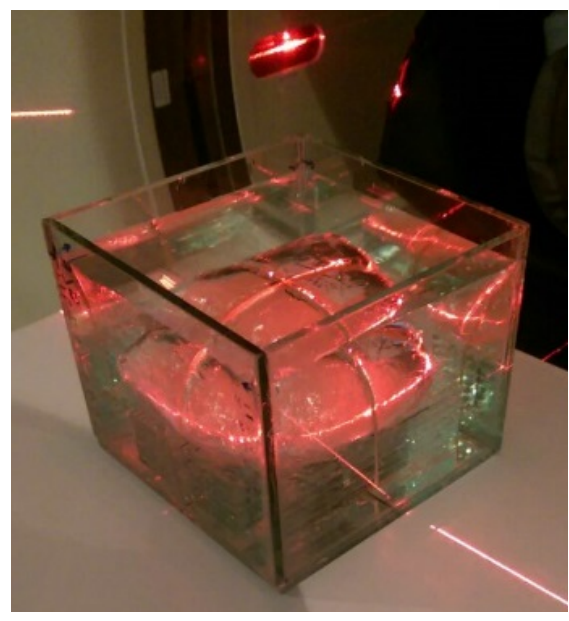

Figure 1 Sample positioning in the tomograph and the linear accelerator.

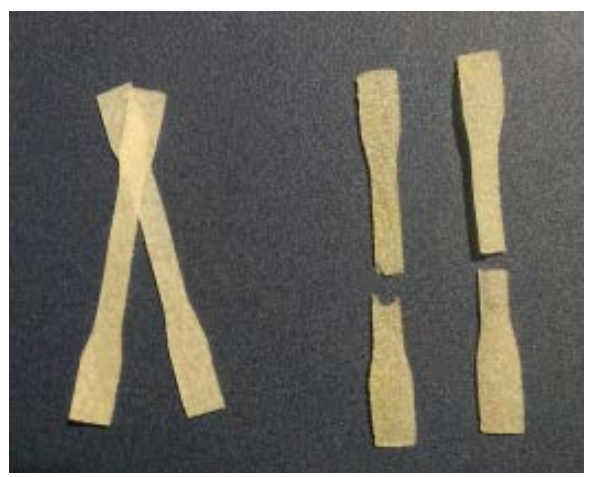

Figure 2 Die cut covering samples, before and after mechanical tests.
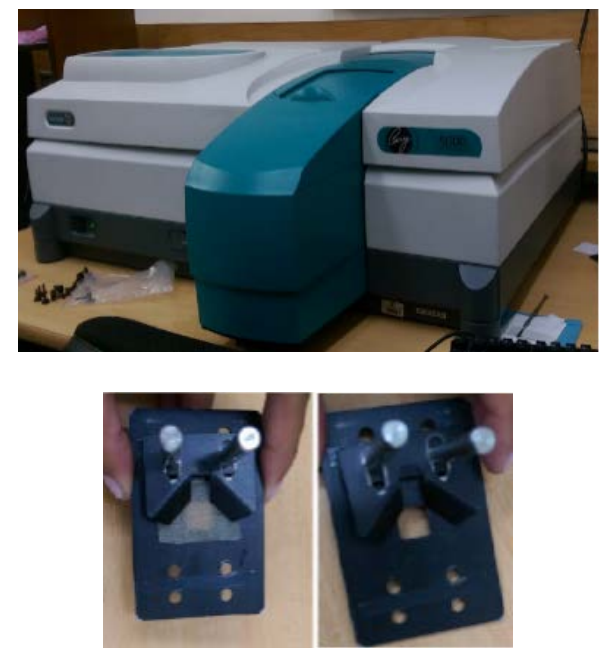

Figure 3 VARIAN Cary5000 Spectrophotometer. Below: Holder with sample.

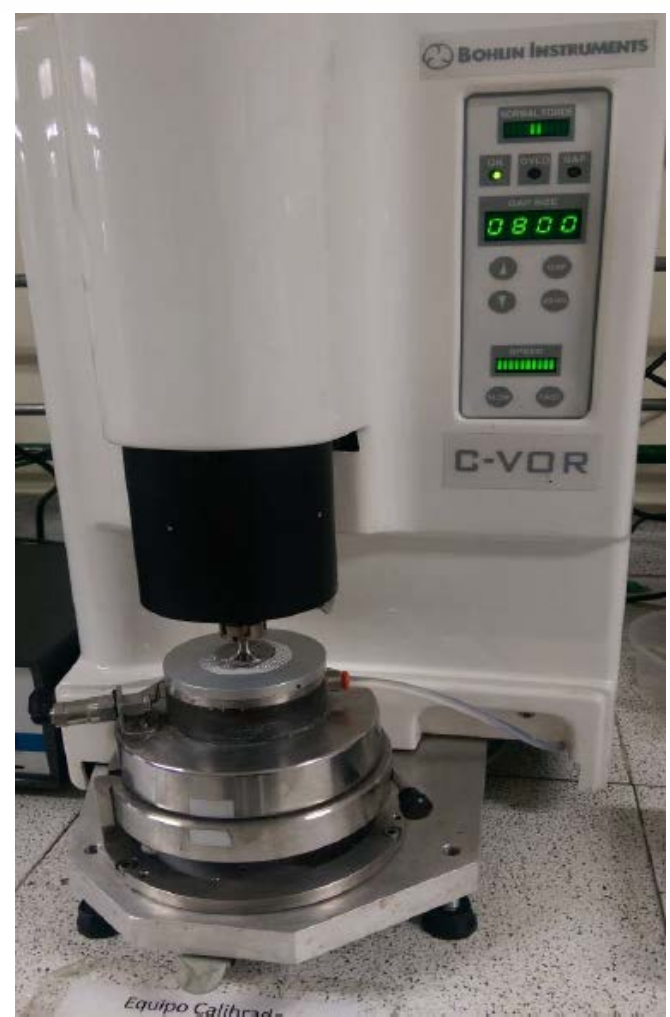

Figure 4 Bohlin Instruments Rheometer, with sample submitted to tension by serrated parallel plates.

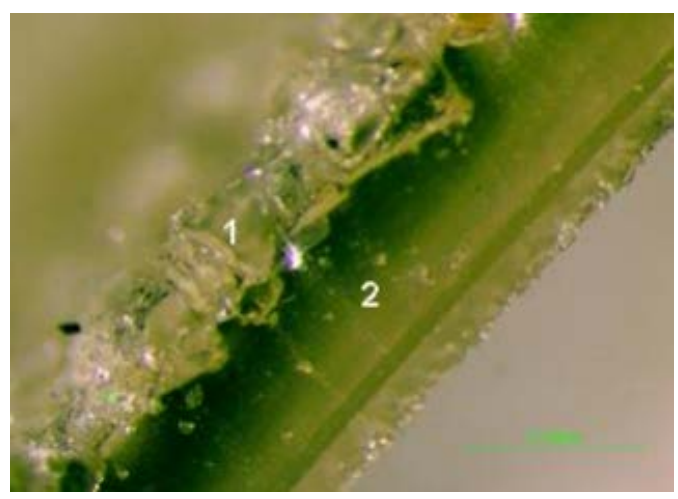

Figure 5 Image of the prosthetic covering obtained through stereoscope. It is observed a rugged irregular area (1) given by a surface treatment (external part of a breast implant), as well as a smooth zone (2). The thickness measure is conducted with a stereoscope with $12 \mathrm{x}$ zoom.

The study evaluates the absorption peaks for the obtained spectra in each test, in a range between $4000-12000(\mathrm{~cm}-$ 1). Using lattice-sized samples for this range, the lamps are changed twice, and in each test a base line is realized. 


\section{TECCIENCIA}

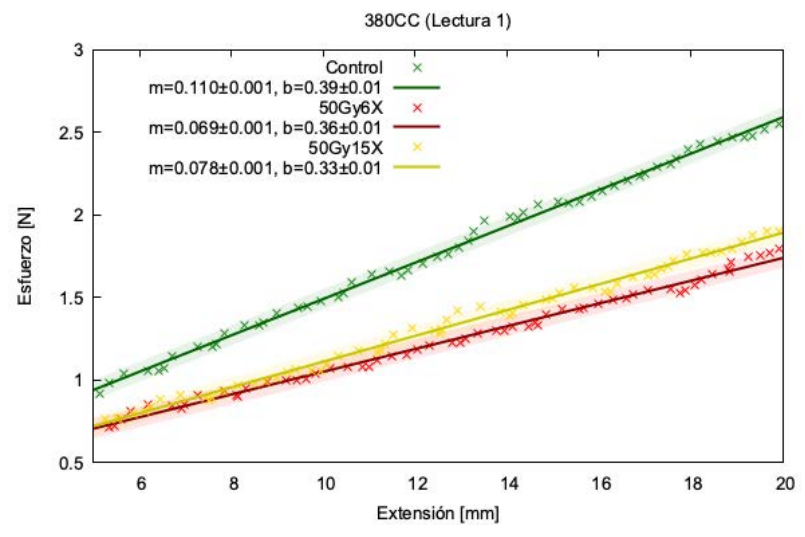

Figure 6 Force as a function of strain for the $380 \mathrm{cc}$ control sample (non-irrradiated).

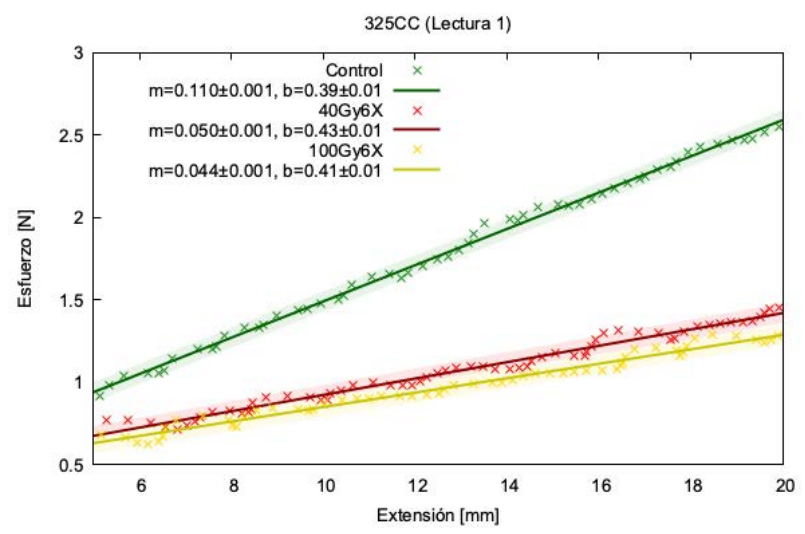

Figure 7 Force as a function of strain for the $325 \mathrm{cc}$ control sample (non-irrradiated)

\subsection{Rheology Tests}

For measuring the viscoelastic response of the prosthetic inner polydimethylsiloxane-based (PDMS) material, a CVOR (Bohlin Instruments) high precision rotational rheometer with up to date calibration is used (Figure 4). Equipment configuration includes a serrated parallel-plate geometry (rugged surface), of $25 \mathrm{~mm}$ diameter, in oscillating mode, where tensions and stresses are applied though oscillations with a frequency sweep between $1-50 \mathrm{rad} / \mathrm{s}$.

The same sinusoidal effort is repeated in one cycle, while the aforementioned frequency sweep is performed. The entire process is conducted at $25^{\circ} \mathrm{C}$, and a waiting period for thermal equilibrium of $30 \mathrm{~s}$.

With the rheometer the material is subjected to controlled strain, shear rate and shear stress. It generates flux curves where one can observe features such as the elastic, viscous and complex modulus, delta, among others.

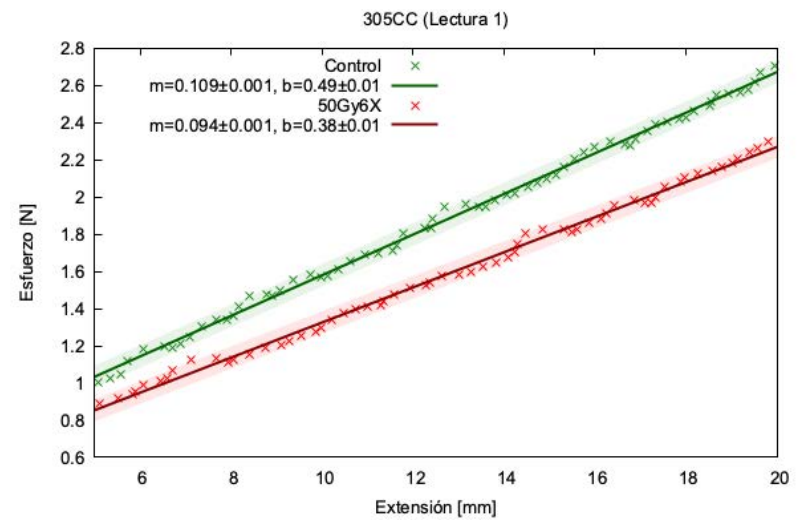

Figure 8 Force as a function of strain for the $305 \mathrm{cc}$ control sample (non-irrradiated)

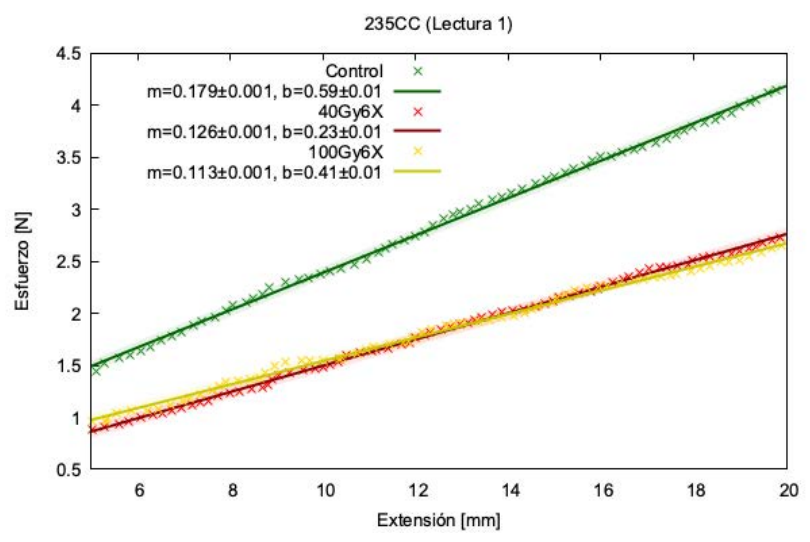

Figure 9 Force as a function of strain for the $235 \mathrm{cc}$ control sample (non-irradiated)

Elastic Modulus, G': Measures the material's elasticity, its capacity to store energy.

$$
G^{\prime}=\left(\frac{\text { stress }}{\text { strain }}\right) \cos \delta
$$

Viscous Modulus, G': Measures the material's capacity to dissipate energy, lost energy as heat.

$G^{\prime \prime}=\left(\frac{\text { stress }}{\text { strain }}\right) \sin \delta$

Delta, $\delta$ : Is the indicative that relates the dissipated energy G' to the stored energy G', the material's damping. Is the phase-lag between the stress-strain curves.

$\tan \delta=\left(\frac{G^{\prime \prime}}{G^{\prime}}\right)$ 


\section{TECCIENCIA}
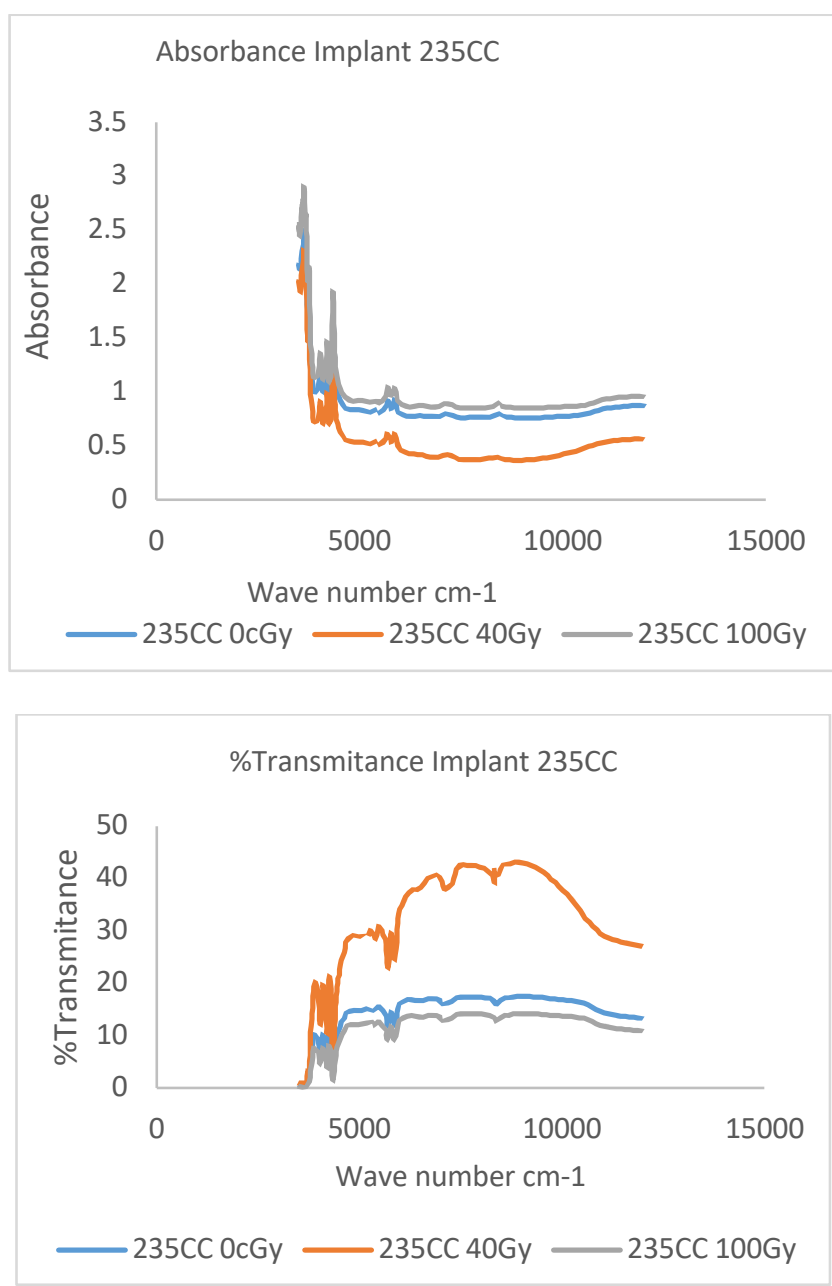

Figure 10 Percentage of transmittance and absorbance as a function of the wave number. $305 \mathrm{cc}$ implant with associated treatments.

If $\delta=0^{\circ}$, the material is elastic, G" and $\mathrm{G}^{\prime}$ are in phase. If $\delta=90^{\circ}$, the material is viscous, there is a $90^{\circ}$ phase-lag between $G^{\prime \prime}$ and $\mathrm{G}^{\prime}$. If $0^{\circ}<\delta<90^{\circ}$, the material is viscoelastic, $G^{\prime \prime}$ and $G^{\prime}$ have a phase-lag between $0^{\circ}$ and $90^{\circ}$ [5], [6].

\subsection{Scanning Electron Microscopy (SEM) Tests}

The inner surface of the covering material is observed. Each sample is covered with gold and graphite to obtain clearer images and avoid stress in the surface that affect the final quality. The samples are stored in laboratory conditions at $20^{\circ} \mathrm{C}$ in a microscopic slide.

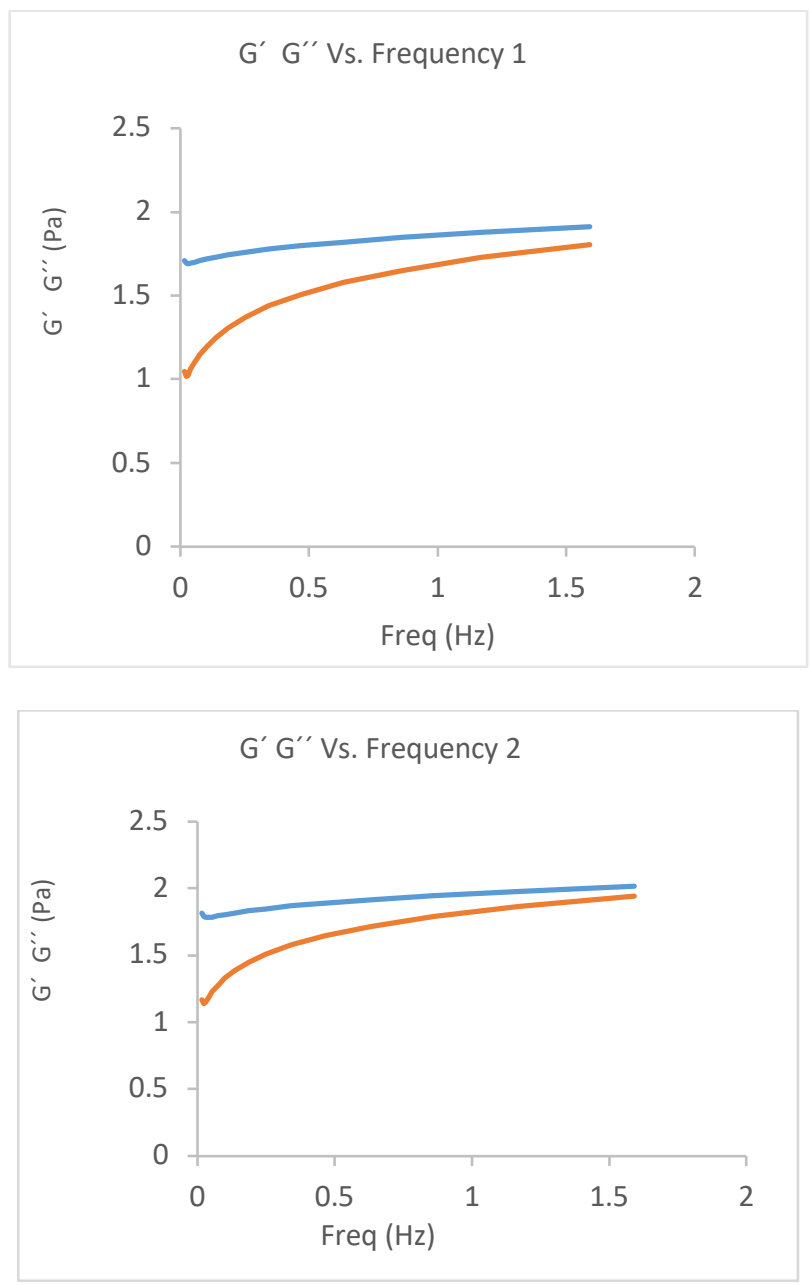

69

Figure 11 Elastic modulus (blue) Vs. Viscous modulus (orange) for the sample $235-40 \mathrm{~Gy}-6 \mathrm{MeV}$ in the first, second and third measurement, respectively.

\section{Results}

The samples are initially observed through an electronic microscope to define configuration parameters in the universal testing machine such as size, thickness, etc. The following image shows an axial view of a cut of covering material.

\subsection{Mechanical Tests}

For the first measurement, mechanical tests were performed on all samples, where fracture strength was in a range between $9 \mathrm{~N}$ to $20 \mathrm{~N}$. 


\section{TECCIENCLA}

Figure 2 represents the results for the implant No. 380, which was subdivided into three samples: 1. Control Sample (non-radiated), 2. Sample radiated with $50 \mathrm{~Gy}$ and $6 \mathrm{MeV}$ energy, and 3. Sample with $50 \mathrm{~Gy}$ and $15 \mathrm{MeV}$ energy. This figure was analyzed for all the available material.

For estimating the uncertainty associated to the measurements, the same test was repeated 4 times. We observed that is tough to guarantee the same conditions for each test, since there are multiple sources of error due, among others, to the position of each sample in the clamps that hold the material, the samples submitted to cutting by a mold or die that could change in small amounts the pressure in each of them, or the zone in the implant from which the material was extracted. The four measurements allowed to estimate an uncertainty of $0.001 \mathrm{MPa}$, as observed in the corresponding results to the slope of each line.

Results showed that the elastic modulus through each line slope has more variations with respect to the dose than with

respect to the energy, where the changes are smaller. The slope of the line for the $380 \mathrm{cc}$ control implant is $0.11 \mathrm{MPa}$, while for the subdivisions radiated with 50Gy at different energies were respectively 0.069 and $0.078(15 \mathrm{MeV})$ (Figure 6). The same behavior was observed for the remaining samples (Figures 7 - 9).

With the results obtained through three measurements in different implants changes were evidenced in the elastic modulus. While there is no strong bias, we observed a decrease with respect to the dose, and the material became less rigid. With respect to the dose, the reduction in the elastic modulus was evidenced for the $380 \mathrm{cc}, 325 \mathrm{cc}$ and $305 \mathrm{cc}$ implants. Results show that the material's elastic modulus changed with the applied radiation dose, but it did not change with time after treatment or measurement

\subsection{Spectrophotometric Test}

Percentages of absorbance and transmittance were collected for each of the samples. Figure 5 shows the obtained spectra for the implant with ID $235 \mathrm{cc}$. No spectral shifts were observed in the characteristic spectra for any sample, therefore there are no changes in the material molecular structure. The maximum transmittance percentage in the $235 \mathrm{cc}$ implant is $45 \%, 35 \%$ in the $305 \mathrm{cc}, 13 \%$ in the $325 \mathrm{cc}$, and $27 \%$ in the $380 \mathrm{cc}$ implant. No changes were observed with respect to the treatment for each implant.

Figure 11 shows the results for the $235 \mathrm{cc}$ implant radiated with 40Gy and $6 \mathrm{MeV}$ energy, where it is observed that the elastic behavior dominates in the studied frequency throughout the three measurements, as well as the control sample.

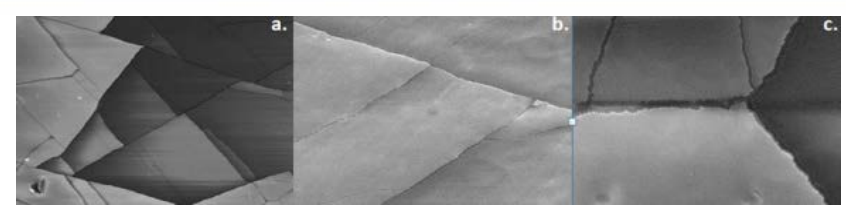

Figure 12 Micrographs of the PDMS covering for the 380 implant control, $50 \mathrm{~Gy}-6 \mathrm{MeV}$ and $50 \mathrm{~Gy}-15 \mathrm{MeV}$ samples, using a $5 \mathrm{kx}, 20 \mu$ magnification. The samples present various cracks with multiple dimensions.

The increase rate of G" is higher with respect to G', which shows a reduction in the difference of values $0.1 \mathrm{~Pa}, 0.06 \mathrm{~Pa}$ and $0.01 \mathrm{~Pa}$, respectively for each measurement, where the viscous modulus tends to dominate towards $1.5 \mathrm{~Hz}$ with time.

The presented changes for the complex modulus are lesser, however decreases in the modulus were presented with respect to the radiation doses and the measurement time.

Both the elastic and viscous modulus present greater curves wih respect to the control. G' and G" increased in the same proportion for each $50 \mathrm{~Gy}-6 \mathrm{MeV}$ and $50 \mathrm{~Gy}-15 \mathrm{MeV}$ treatment, with respect to the control sample, which indicates that the irradiated energy does not affect the modulus but the radiation dose does, although it should be noted that the changes are below $5 \%$.

\subsection{Scanning Electron Microscopy (SEM)}

Figure 12 shows micrographs obtained through SEM. In all images we observed surfaces with cracks both in the control samples as well as in the treated samples. This appearance is also constant with time, no significant changes were appreciated with treatment or measurement times. Different magnifications were used according to the behavior of the sample in the equipment. In some occasions the sample was placed and the image appeared bright and low-quality. The average size of the crack was determined for each micrograph, but they were not comparable to each other, since the evaluated zone is not exactly the same and the magnifications employed are in the $\mathrm{Kx}$ order, where scales are below 20 microns.

This test showed no changes in the silicone material. No significant modifications were observed in its morphology or composition after radiotherapy treatment, since the cracks of different sizes were always present in all the samples.

Additionally, the SEM equipment has a x-ray dispersion system that detects chemical elements with atomic number above 8 . 


\section{TECCIENCIA}

Through the analysis, complementary qualitative information was presented on the compound of the implant covering material, and whether it is within the aforementioned atomic number. Obtained signals are mainly from Oxygen $(\mathrm{O})$ and Silicon $(\mathrm{Si})$.

Is important to consider that the atomic number corresponding to Carbon (C) is not available in the detector, since the samples are fixed with a carbon tape before they are placed in the detection chamber. The predominance of present elements in the material is observed, and the accounted silicon and oxygen did not vary for each test. Also, it should be noted that the strict counting of $\mathrm{Si}$ and $\mathrm{O}$ is not absolute, which makes this a qualitative analysis.

\section{Conclusions}

Though the mechanical tests performed, we evidenced a decrease in the maximum stress necessary to achieve material breaking, as well as a decrease in the elastic modulus as a function of radiation dose: the higher the dose, the lower the elastic modulus, and the lower the breaking force. No changes were observed with respect to the radiated energy.

Through the spectrophotometry tests, a characterization was conducted for the percentage of transmittance and absorbance in a range between 4000 and $12000 \mathrm{~cm}-1$, the absorption spectra did not present any spectral shifts, which indicates the material was not modified.

Through Scanning Electron Microscopy tests, we observed the inner surface of the covering for each implant. Micrographs were obtained using $5 \mathrm{kx}, 10 \mu$ magnification, where we observed surfaces with cracks in the control samples as well as in the treated samples. This appearance is constant also with time. No significant changes were evidenced with respect to treatment, or time of measurements.

Through rheology tests the inner material for each implant was evaluated. When observing the viscous modulus for all samples after each measurement, its growth rate tends to increase and even surpass the material's elastic behavior curve as a function of time; We observe a tendency of the viscous modulus to dominate with time. With respect to the dose, the G' and G' modulus present a slight increase after the application of the radiation dose. No effect in either modulus is present with respect to the energy.

The form in which the breast implants are produced is through curing, which makes each implant different from others, even for a pair of implants coming from the same batch. Thus, one of the bigger limitations is the available material for sample comparison. It is suggested to conduct an estimate of the measurement uncertainty, as well as using bigger implants, therefore reducing the limitation in material quantity, in order to review the obtained results for longer measurements and for more tests.

\section{Acknowledgements}

We thank the Medical Physics group at Universidad Nacional de Colombia, as well as Cesar Augusto Bacca as a Professional Support in the Interfaculty Mechanical Test Laboratory, also at Universidad Nacional de Colombia. We also thank Professor Luis Alejandro Boyacá, who enabled the work in the Polymer Laboratory at the Faculty of Engineering, and Professor Ángel Miguel Ardila, who facilitated the permit for conducting optical tests in the Physics Department at the Faculty of Sciences.

\section{References}

[1] A.Taboada Suárez.(2012). Influencia multifactorial en el desarrollo de contractura capsular, rotura protésica y complicaciones menores de las prótesis - expansoras en la reconstrucción de mama (Tesis de postgrado, Doctoral). Universidad Santiago de Compostela, España 1

[2] Acea Nebrila Benigno. et, Al.(2014). Evaluación de un programa de reconstrucción mamaria inmediatamediante expansión-prótesis en mujeres con cáncer de mama. Revista de Senología y Patología Mamaria. (27), (p.10-18) [2]

[3] Algara López Manuel, Pinero Antonio Madrona b, Ramos Juan Salinas \& Bajo d. Gregorio Gómez,(2012). Radioterapia y técnicas de reconstrucción mamaria. Revista de Senología y Patología Mamaria, (26)1, (25-32).

[4] ASTM Standard D638-14 . Standard Test Method for Tensile Properties of Plastics1, ASTM International, 2014.

[5] Mezger T, The Rheology Handbook: For users of rotational and oscillatory rheometers. 2nd revised edition, Vincentz Network, Hannover, 2006. (p. 118-119)

[6] Mezger T, The Rheology Handbook: For users of rotational and oscillatory rheometers. 2nd revised edition, Vincentz Network, Hannover, 2006. (p. 122) 